\title{
Analisa Distribusi Stress dan Displacement pada Sudu Turbin Angin Savonius dengan Material Baja Menggunakan Simscale
}

\author{
Ferdian Sutanto $^{1}$, Adimas Wicaksana ${ }^{1}$, dan Anggito Pringgo Tetuko ${ }^{2}$ \\ ${ }^{1}$ Program Studi Teknik Mesin, Universitas Pamulang, Jl. Surya Kencana No.1, Pamulang 15417, \\ Tangerang Selatan, Indonesia. \\ ${ }^{2}$ Pusat Penelitian Fisika, Lembaga Ilmu Pengetahuan Indonesia, Serpong 15314, Tangerang Selatan, \\ Indonesia. \\ E-mail : ferdiansutanto27@gmail.com
}

\begin{abstract}
Abstrak: Hasil penelitian analisa sudu menggunakan aplikasi Simscale dengan metode Finite Element Analysis (FEA), hasil output berupa Von Mises Stress dan Displacement. Material sudu baja AISI 1018 Mild, dengan variasi dimensi desain sudu, kecepatan angin $50 \mathrm{~m} / \mathrm{s}$. Variabel terikatnya adalah daya, torsi, rpm dan gaya. Simulasi yang dipilih adalah dynamic dengan boundary condition yaitu force dan fixed support. Nilai maksimum von mises stress tertinggi terjadi pada desain sudu $\mathrm{F}$ sebesar $943204 \mathrm{~Pa}$ dan terendah pada desain sudu A sebesar $235260 \mathrm{~Pa}$. Nilai maksimum displacement tertinggi terjadi pada desain sudu F sebesar 4,93E-06 m terendah pada desain sudu A sebesar 8,87E-07 m. Desain sudu F merupakan desain terbaik dengan distribusi stress dan displacement terendah. Simulasi yang dilakukan masih dalam batas aman mechanical properties baja AISI 1018 Mild. Angin memiliki pengaruh terhadap besar daya yang dihasilkan masing - masing desain sudu.
\end{abstract}

Kata kunci: Energi Angin, Turbin Angin Savonius, Simulasi Simscale, Finite Element Analysis (FEA) Distribusi Stress dan Displacement, Baja AISI 1018 Mild.

\begin{abstract}
The results of the blade analysis research using the Simscale application with the Finite Element Analysis (FEA) method, The output results are in the form of Von Mises Stress and Displacement. AISI 1018 Mild steel blade material, with variations in blade design dimensions, wind speed of $50 \mathrm{~m} / \mathrm{s}$. The dependent variables are power, torque, rpm and force. The simulation chosen is dynamic with boundary conditions, namely force and fixed support. The maximum value of von mises stress occurs at the design of blade F of $943204 \mathrm{~Pa}$ and the lowest is at the design of blade A of $235260 \mathrm{~Pa}$. The highest maximum displacement value occurred at the F blade design of $4.93 \mathrm{E}-06 \mathrm{~m}$, the lowest was at the A blade design of $8.87 \mathrm{E}-07 \mathrm{~m}$. The F blade design is the best design with the lowest stress distribution and displacement. The simulations carried out are still within safe limits of AISI 1018 Mild steel mechanical properties. Wind has an influence on the amount of power generated by each blade design.
\end{abstract}

Keywords: Wind Energy, Savonius Wind Turbine, Simscale Simulation, Finite Element Analysis (FEA), Stress Distribution and Displacement, AISI 1018 Mild Steel.

\section{PENDAHULUAN}

Angin merupakan udara yang bergerak akibat terdapatnya perbedaan tekanan udara antara tempat yang mempunyai tekanan tinggi ke tempat yang bertekanan rendah ataupun dari wilayah dengan suhu atau temperatur rendah ke tinggi. Perbedaan tekanan udara juga dipengaruhi oleh sinar matahari. Angin mempunyai energi kinetik sebab udara mempunyai massa m serta bergerak dengan kecepatan $\mathrm{v}$ [1].

Turbin angin merupakan suatu sistem yang berfungsi untuk mengubah energi kinetik angin menjadi energi mekanik pada poros turbin angin tersebut. Energi angin dikonversi sebagian menjadi tenaga putar oleh rotor. 
Dengan ataupun tanpa roda gigi, putaran rotor tersebut umumnya digunakan untuk memutar generator yang akan menghasilkan energi listrik [2].

Berdasarkan dari bentuk rotor, turbin angin dibagi menjadi 2 jenis, ialah Turbin Angin Sumbu Horizontal (TASH) serta Turbin Angin Sumbu Vertikal (TASV) [3].

Turbin angin Savonius merupakan salah satu jenis turbin angin sumbu vertikal yang ditemukan sebagai pemanfaatan untuk energi yang lebih effisien, dapat menerima potensi angin dari segala arah dan dapat bekerja pada kecepatan rendah. Prinsip kerja turbin Savonius yaitu bersumber pada differential drag windmill [4].

Dalam pengoperasian di lapangan sudu merupakan salah satu bagian paling penting dan utama pada turbin angin yang harus memiliki desain terbaiknya agar optimal untuk menerima angin berkecepatan rendah maupun tinggi dan pemilihan material yang kuat untuk menahan kecepatan angin yang tinggi dan juga harus mampu bergerak pada angin kecepatan rendah sekalipun.

Penelitian ini bertujuan untuk mengetahui bagaimana pengaruh desain sudu terhadap distribusi stress dan displacement, mengetahui distribusi stress dan displacement pada desain sudu yang menggunakan material baja apakah masih dalam batasan aman untuk digunakan dan mengetahui pengaruh kecepatan angin terhadap sudu yang digunakan.

\section{METODOLOGI}

Sudu turbin angin savonius yang digunakan adalah sudu tipe U dengan beberapa variasi ukuran desain, aplikasi yang digunakan untuk simulasi adalah Simscale. Simscale merupakan aplikasi simulasi rekayasa online berbasis browser yang menyediakan pemodelan serta simulasi. Dengan visualisasi 3D dalam browser, kapasitas untuk komputasi sesuai permintaan dapat diskalakan. Simscale dapat melakukan simulasi Computational Fluid Dynamics (CFD), Finite Element Analysis (FEA) dan Thermal Simulation [5][6]. Dalam hal ini simulasi yang digunakan adalah Finite Element Analysis dengan jenis pembebanan yaitu dynamic, boundary condition yaitu force dan fixed support.

Finite Element Analysis (FEA) ialah pendekatan numerik untuk mendapatkan nilai tegangan dari perpindahan suatu struktur. Struktur dipecah menjadi elemen - elemen kecil yang mempunyai titik nodal di setiap elemen. Titik nodal tersebut digunakan untuk menyambung elemen kecil dengan elemen kecil yang lain sehingga menjadi suatu struktur. Apabila dicoba pemberian beban pada struktur maka nodal akan merespon tegangan dengan perpindahan. Nilai perpindahan tiap nodal dikonversi menjadi sebuah nilai tegangan. Apabila digunakan adalah elemen yang kecil maka jumlah nodal akan menjadi semakin banyak, sehingga perhitungan suatu elemen akan semakin akurat [7]. berikut:

Untuk mencari nilai yang di gunakan pada force yaitu nilai gaya pada simulasi, digunakan rumus sebagai

\section{Tenaga Kincir Angin [8]}

$$
P=0,5 \times \rho \times A \times C p \times v^{3} \times \eta e \times \eta m
$$

Dimana:

$\mathrm{P} \quad=$ Tenaga dalam $(\mathrm{W})$

$\rho=\quad=$ Density udara $\left(1,225 \mathrm{~kg} / \mathrm{m}^{3}\right)$

A $=$ Luas $\left(\mathrm{m}^{2}\right)$

$\mathrm{Cp} \quad=$ Koefisien kerja

$\mathrm{v}=$ Kecepatan angin dalam $\mathrm{m} / \mathrm{s}$

$\eta e \quad=$ Efisiensi listrik

$\eta m=$ Efisiensi mekanik

Luas Rotor [8]

Dimana :

$$
A=D \times H
$$

$\mathrm{D}=$ Diameter turbin $(\mathrm{m})$

$\mathrm{H} \quad=$ Tinggi turbin $(\mathrm{m})$

Torsi [8]

Dimana :

$$
T=F \times R
$$

$\mathrm{T}=$ Torsi benda berputar (N.m)

$\mathrm{F} \quad$ = Gaya $(\mathrm{N})$

$\mathrm{R}=$ Jari - jari $(\mathrm{m})$ 
58 | Ferdian Sutanto, dkk., Analisa Distribusi Stress dan Displacement pada ....,

$$
T=\frac{P}{\omega}
$$

Dimana, P adalah daya keluaran dan $\omega$ kecepatan sudut diberikan sebagai berikut :

$$
\omega=\frac{2 \pi n}{60}
$$

Dimana n adalah kecepatan rotasi dalam rpm. Dengan mengganti nilai - nilai ini, kita mendapatkan

$$
T=9,55 \frac{P}{n}
$$

Dimana P berada dalam kilowatt $(\mathrm{kW})$

\section{Perhitungan Kecepatan Rotasi [8]}

$$
\begin{aligned}
& T=9,55 \times 10^{6} \frac{P}{n} \\
& v=R \omega \text { and } \omega=\frac{2 \pi n}{60}
\end{aligned}
$$

Dari sini didapat

Dimana v adalah kecepatan.

$$
n=\frac{60}{\pi} \frac{v}{2 R}
$$

\section{Nilai Asumsi [9]}

Nilai asumsi yang akan digunakan untuk pemodelan dan analisis dinyatakan dibawah ini:

1. Kecepatan angin yang akan digunakan adalah $50 \mathrm{~m} / \mathrm{s}$.

2. Koefisien kerja (Cp) 0,3.

3. Efisiensi listrik dan mekanik diambil masing 0,95 dan 0,90 .

4. Untuk luas (A) akan mengikuti desain sudu.

5. Density udara yang digunakan adalah $1,225 \mathrm{~kg} / \mathrm{m}^{3}$.

\section{Material Yang Digunakan}

Simulasi desain sudu turbin angin savonius yang digunakan adalah material baja dengan asumsi baja AISI 1018 Mild, berikut ini adalah tabel dari mechanical properties baja AISI 1018 Mild:

Tabel 1. Mechanical Properties Baja AISI 1018 Mild / Low Carbon Steel [9]

\begin{tabular}{lcc|}
\hline Mechanical Properties & Metric & Imperial \\
\hline Hardness, Brinell & 126 & 126 \\
\hline Hardness, Knoop (Converted from Brinell hardness) & 145 & 145 \\
\hline Hardness, Rockwell B (Converted from Brinell hardness) & 71 & 71 \\
\hline Hardness, Vickers (Converted from Brinell hardness) & 131 & 131 \\
\hline Tensile Strength, Ultimate & $440 \mathrm{MPa}$ & $63800 \mathrm{psi}$ \\
\hline Tensile Strength, Yield & $370 \mathrm{MPa}$ & $53700 \mathrm{psi}$ \\
\hline Elongation at Break (In 50 mm) & $15.0 \%$ & $15.0 \%$ \\
\hline Reduction of Area & $40.0 \%$ & $40.0 \%$ \\
\hline Modulus of Elasticity (Typical for steel) & $205 \mathrm{GPa}$ & $29700 \mathrm{ksi}$ \\
\hline Bulk Modulus (Typical for steel) & $140 \mathrm{GPa}$ & $20300 \mathrm{ksi}$ \\
\hline Poissons Ratio (Typical For Steel) & 0.290 & 0.290 \\
\hline Machinability (Based on AISI 1212 steel. as 100\% machinability) & $70 \%$ & $70 \%$ \\
\hline Shear Modulus (Typical for steel) & $80.0 \mathrm{GPa}$ & $11600 \mathrm{ksi}$
\end{tabular}

\section{Desain Sudu Yang Akan Disimulasikan}
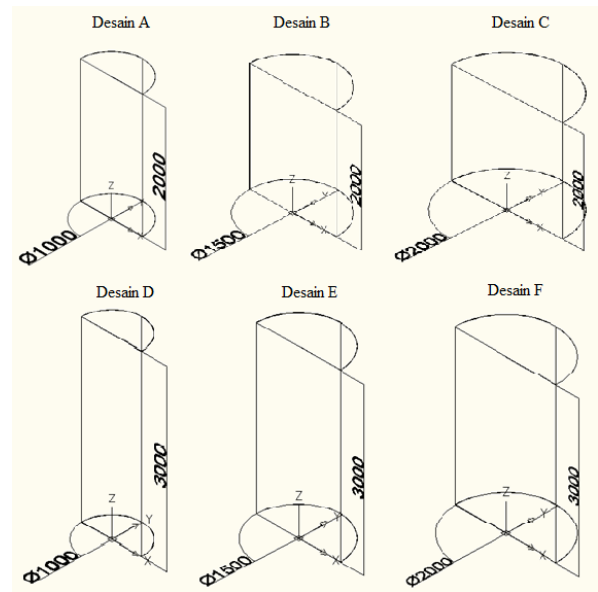

Gambar 1. Desain sudu yang akan disimulasikan 


\section{HASIL DAN DISKUSI}

Data di bawah ini adalah hasil perhitungan dari rumus dan nilai asumsi sehingga diperoleh data dengan nilai yang dapat dilihat pada tabel berikut ini:

Tabel 2. Hasil Perhitungan Untuk Mendapatkan Gaya

\begin{tabular}{ccccccc}
\hline Desain & $\begin{array}{c}\text { Kecepatan } \\
\text { Angin (M/S) }\end{array}$ & Daya (W) & Daya (Kw) & Rpm & Torsi (N.Mm) & Gaya (N) \\
\hline A & 50 & 39276,56 & 39,3 & 955 & 393000 & 786 \\
B & 50 & 58914,84 & 58,9 & 637 & 883038 & 1177 \\
C & 50 & 78553,13 & 78,6 & 478 & 1570356 & 1570 \\
D & 50 & 58914,84 & 58,9 & 955 & 589000 & 1178 \\
E & 50 & 88372,27 & 88,4 & 637 & 1325306 & 1767 \\
F & 50 & 117829,69 & 117,8 & 478 & 2353536 & 2354 \\
\hline
\end{tabular}

Di dapat nilai gaya untuk mensimulasikan desain sudu turbin, nilai gaya di masukkan pada boundary condition yaitu untuk force dan fixed support untuk memilih tumpuan pada sudu, pada gambar $2-7$ adalah hasil dari simulasi Simscale.

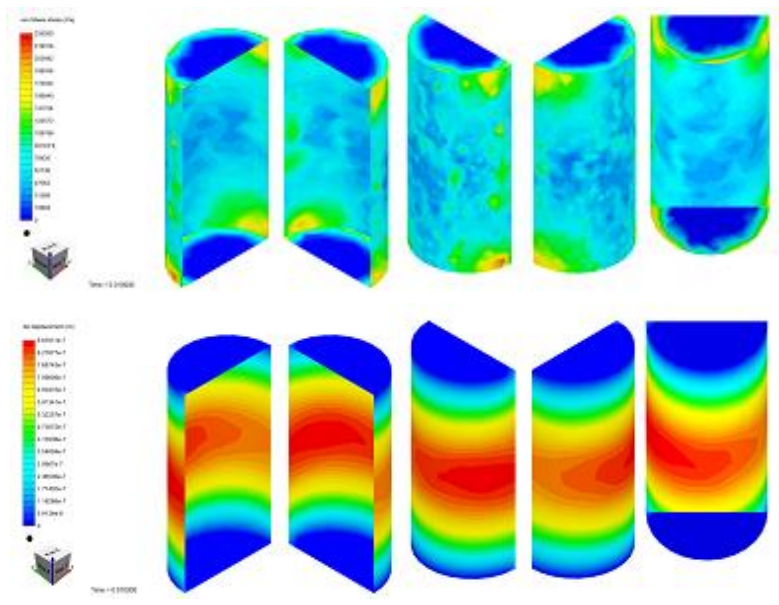

Gambar 2. Distribusi stress dan displacement yang terjadi pada desain A

Desain sudu A dapat diamati pada bagian lekukan antara tumpuan sudu dengan sudu turbin, meluas pada area sudut sudu dan sisi sudu, bagian tersebut terjadi distribusi stress tinggi dengan nilai maksimum stress pada sudu sebesar $235260 \mathrm{~Pa}$ dan displacement tertinggi terjadi pada tengah sudu dengan nilai maksimum displacement sebesar 8,87E-07 m.

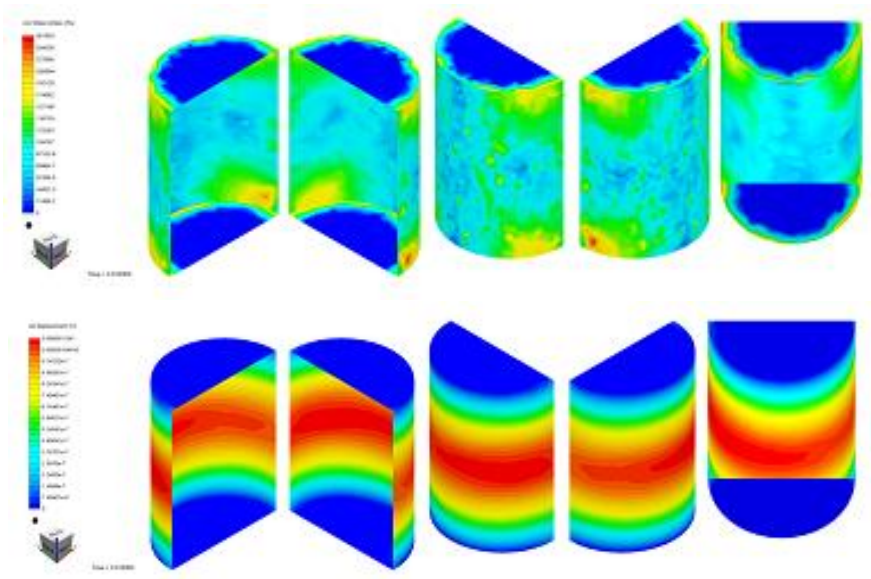

Gambar 3. Distribusi stress dan displacement yang terjadi pada desain B 
Desain sudu B dapat diamati pada bagian lekukan antara tumpuan sudu dengan sudu turbin, meluas pada area sudut sudu dan sisi sudu, bagian tersebut terjadi distribusi stress tinggi. Dibandingkan desain sudu A, desain sudu B terjadi distribusi stress lebih tinggi dan luas yang di tunjukkan oleh warna hijau, kuning dan merah dengan nilai maksimum stress pada sudu sebesar $261993 \mathrm{~Pa}$ dan displacement tertinggi terjadi pada tengah sudu dengan nilai maksimum displacement sebesar 1,12E-06 m.

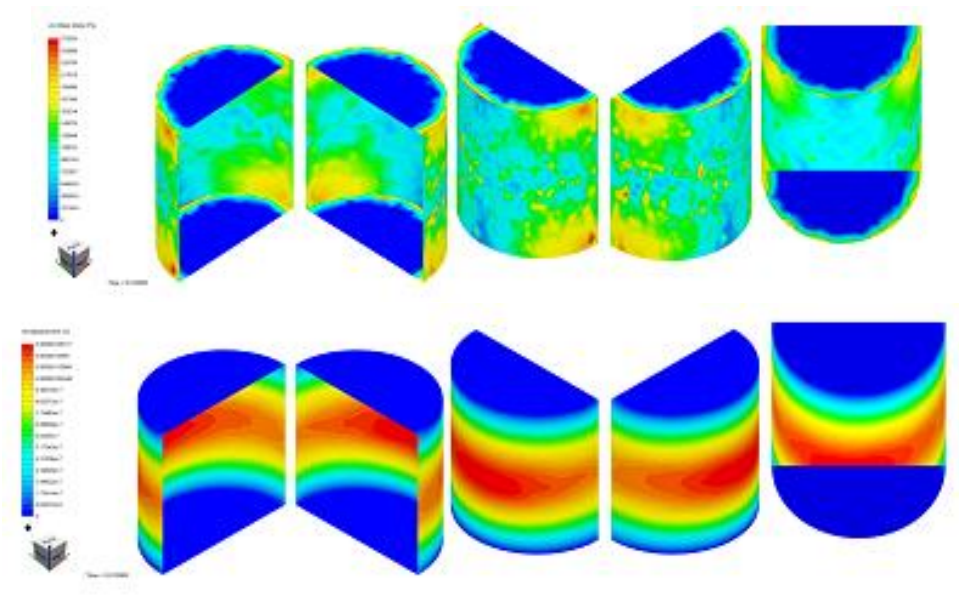

Gambar 4. Distribusi stress dan displacement yang terjadi pada desain C

Desain sudu C dapat diamati pada bagian lekukan antara tumpuan sudu dengan sudu turbin, meluas pada area sudut sudu dan sisi sudu, bagian tersebut terjadi distribusi stress tinggi. Dibandingkan desain sudu B, desain sudu $\mathrm{C}$ terjadi distribusi stress lebih tinggi dan luas yang di tunjukkan oleh warna hijau, kuning dan merah dengan nilai maksimum stress pada sudu sebesar $272024 \mathrm{~Pa}$ dan displacement tertinggi terjadi pada tengah sudu dengan nilai maksimum displacement sebesar 1,29E-06 m.

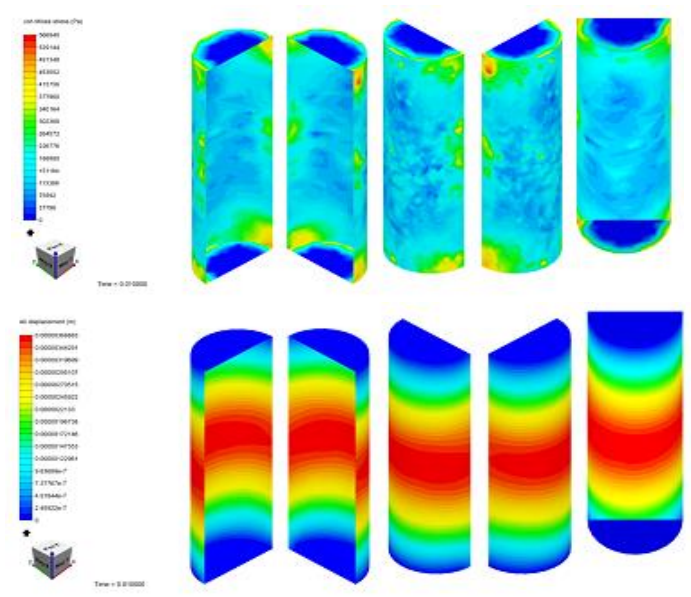

Gambar 5. Distribusi stress dan displacement yang terjadi pada desain D

Desain sudu D dapat diamati pada bagian lekukan antara tumpuan sudu dengan sudu turbin, meluas pada area sudut sudu dan sisi sudu, bagian tersebut terjadi distribusi stress tertinggi. Dibandingkan desain sudu A, B dan $\mathrm{C}$, desain sudu $\mathrm{D}$ distribusi terpusat mengalami pengurangan yang di tunjukkan warna hijau, kuning dan merah dengan nilai maksimum stress pada sudu sebesar $566940 \mathrm{~Pa}$ dan displacement tertinggi terjadi pada tengah sudu dengan nilai maksimum displacement sebesar 3,69E-06 m. 


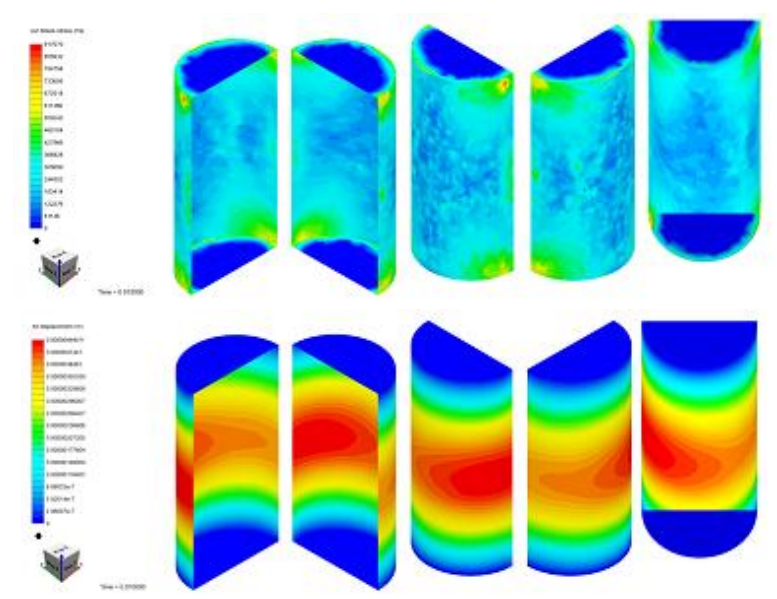

Gambar 6. Distribusi stress dan displacement yang terjadi pada desain E

Desain sudu E dapat diamati pada bagian lekukan antara tumpuan sudu dengan sudu turbin, meluas pada area sudut sudu dan sisi sudu, bagian tersebut terjadi distribusi stress tinggi. Dibandingkan desain sudu A, B, C, dan $\mathrm{D}$, desain sudu $\mathrm{E}$ distribusi terpusat mengalami pengurangan yang di tunjukkan warna hijau, kuning dan merah dengan nilai maksimum stress pada sudu sebesar $917070 \mathrm{~Pa}$ dan displacement tertinggi terjadi pada tengah sudu dengan nilai maksimum displacement sebesar 4,44E-06 m.

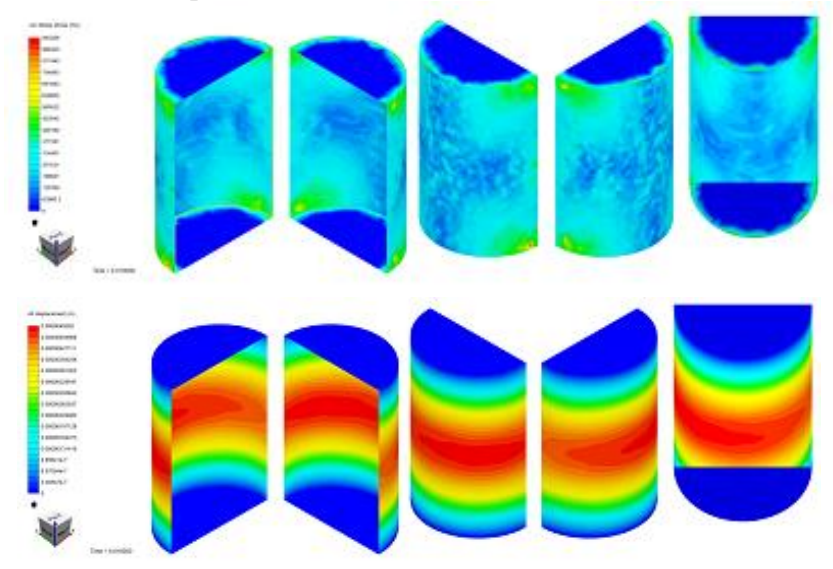

Gambar 7. Distribusi stress dan displacement yang terjadi pada desain F

Desain sudu F dapat diamati pada bagian lekukan antara tumpuan sudu dengan sudu turbin, meluas pada area sudut sudu dan sisi sudu, bagian tersebut terjadi distribusi stress tinggi. Dibandingkan desain sudu A, B, C, $\mathrm{D}$, dan $\mathrm{E}$, desain sudu $\mathrm{F}$ distribusi terpusat mengalami pengurangan yang di tunjukkan warna hijau, kuning dan merah dengan nilai maksimum stress pada sudu sebesar $943204 \mathrm{~Pa}$ dan displacement tertinggi terjadi pada tengah sudu dengan nilai maksimum displacement sebesar 4,93E-06 m.

Hasil simulasi dapat disimpulkan dengan variasi ukuran desain sudu di dapatkan ukuran yang tepat akan menghasilkan distribusi yang optimal terutama pada desain sudu F. Pada jurnal penelitian sebelumnya dengan variasi desain sudu di dapat bahwa ukuran memiliki pengaruh terhadap distribusi stress dan displacement. [5]

Von Mises Stress (Pa)

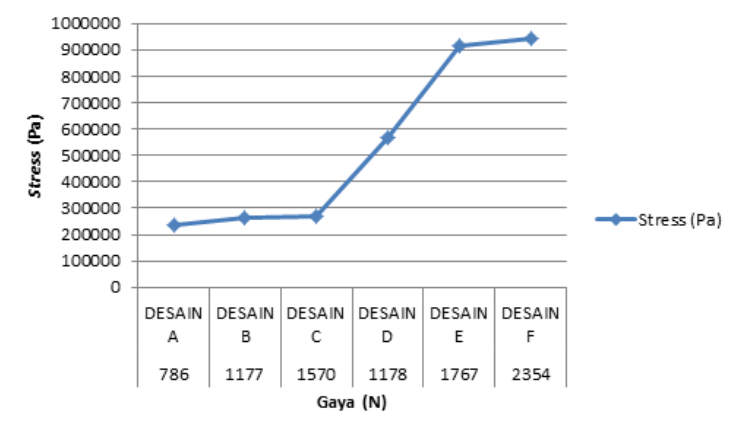

Gambar 8. Grafik hubungan besar gaya sudu terhadap maksimum von mises stress 
62 | Ferdian Sutanto, dkk., Analisa Distribusi Stress dan Displacement pada ....,

Grafik di atas menunjukkan von mises stress cenderung menaik sesuai dengan penambahan luas dan gaya pada sudu. Von mises stress tertinggi terjadi pada desain sudu F sebesar $943204 \mathrm{~Pa}$ dengan luas sudu $6 \mathrm{~m}$ dan gaya 2354 N. Sedangkan von mises stress terendah terjadi pada desain sudu A sebesar 235260 Pa dengan luas sudu $2 \mathrm{~m}$ dan gaya $786 \mathrm{~N}$.

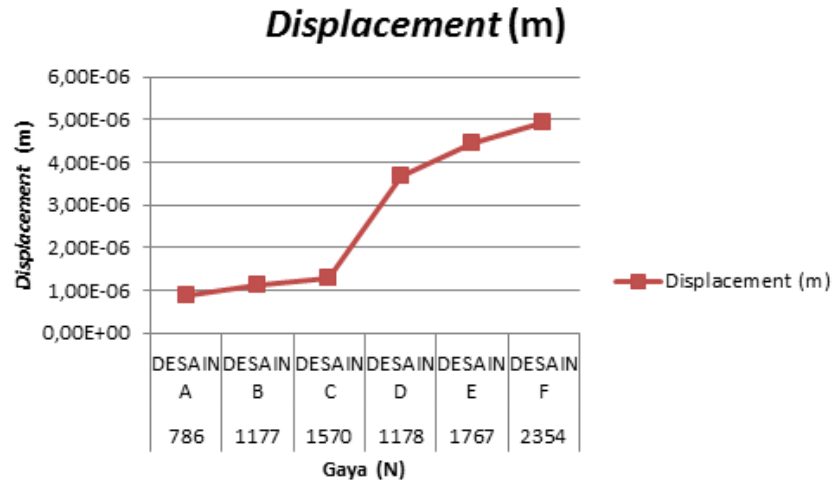

Gambar 9. Grafik hubungan besar gaya sudu terhadap maksimum displacement

Grafik di atas menunjukkan displacement cenderung menaik sesuai dengan penambahan luas dan gaya pada sudu. Displacement tertinggi terjadi pada desain sudu F sebesar 4,93E-06 m dengan luas sudu $6 \mathrm{~m}$ dan gaya $2354 \mathrm{~N}$. Sedangkan displacement terendah terjadi pada desain sudu A sebesar 8,87E-07 m dengan luas sudu $2 \mathrm{~m}$ dan gaya $786 \mathrm{~N}$.

Dari hasil simulasi Simscale didapat nilai maksimum von mises stress dan displacement. Dengan hasil tersebut dapat di analisa semua desain sudu yang di simulasikan dengan asumsi baja AISI 1018 Mild yaitu dapat kuat menahan beban maksimal pada simulasi. Dalam hal ini analisa yang dilakukan adalah dengan membandingan hasil maksimum von mises stress dan displacement untuk mengetahui apakah hasil simulasi dalam batas aman pada properties baja AISI 1018 Mild. Dan kecepatan angin memiliki pengaruh terhadap sudu yang digunakan, dimana semakin luas sudu yang digunakan maka semakin besar daya yang dihasilkan.

\section{KESIMPULAN}

Ukuran desain sudu memiliki pengaruh terhadap distribusi stress dan displacement, dengan variasi ukuran desain sudu yang dilakukan dapat disimpulkan bahwa sudu harus memiliki ukuran yang terbaik agar distribusi stress dan displacement dapat merata pada semua bagian sudu. Distribusi stress dan displacement pada semua desain sudu yang menggunakan material baja aman untuk digunakan dan dilihat dari nilai maksimum stress dan displacement di semua sudu dibandingkan dengan mechanical properties baja AISI 1018 Mild sudu dapat kuat menahan beban maksimal pada simulasi. Kecepatan angin memiliki pengaruh terhadap sudu yang digunakan, semakin luas sudu yang digunakan maka semakin besar daya dan gaya, nilai gaya ini yang akan berpengaruh pada hasil simulasi.

\section{UCAPAN TERIMA KASIH}

Penulis mengucapkan terima kasih kepada Program Studi Teknik Mesin-Universitas Pamulang dan Pusat Penelitian Fisika-Lembaga Ilmu Pengetahuan Indonesia atas dukungan dalam penelitian ini.

\section{DAFTAR PUSTAKA}

[1] T. A. F. Soelaiman, N. P. Tandian, and N. Rosidin, "Perancangan, Pembuatan dan Pengujian Prototipe SKEA Menggunakan Rotor Savonius dan Windside untuk Penerangan Jalan Tol,” Semin. Nas. Tah. Tek. Mesin, SNTTM-VI, pp. 246-251, 2007.

[2] J. Sargolzaei, "Prediction of The Power Ratio in Wind Turbine Savonius Rotors Using Artifical Neural Networks", Zahedan: Baluchestan University, 2007.

[3] Y. Daryanto, "Kajian Potensi angin Untuk Pembangkit Listrik Tenaga Bayu,” Blueprint, April, 2007. 
[4] B. Mahendra, "Pengaruh Jumlah Sudu Terhadap Unjuk Kerja Turbin Angin Savonius Type L", Malang, 2011.

[5] S. Wasserman, "SimScale Brings the Price of Computer-Aided Engineering Down to Zero", engineering.com, 2015.

[6] R. Tara, "Be Warned: The CAE World Is About to Shift", engineering.com, 2016.

[7] S. S. H. Moel, "Analisis Komputasional Mekanika Retak Pada Pelat Metal Berlubang Berpenambal Metal dan Komposit”, Skripsi, FTMD, Teknik Mesin, Institut Teknologi Bandung. Bandung, Indonesia, 2017

[8] P. Gipe, "Wind power renewable energy for home farm and business", Chelsia Green Publication Company, White River Junction, VT, Page no. 61, 2004

[9] S. Mitra, P. Laws, B. Aditya, and R. V. Bethi, "Parametric sensitivity analysis of vertical axis wind turbine," Int. J. Mech. Eng. Robot. Res., vol. 6, no. 5, pp. 385-390, 2017.

[10] https://www.azom.com/article.aspx?ArticleID=6115 